\title{
A Study on Patterns of Compensatory Articulation Errors with Reference to Age of Surgery in Children with Repaired Cleft Lip and Palate
}

\author{
K Govathi Nikhila* and Hari Prasad \\ Ali Yavar Jung National Institute for the Hearing Handicapped, Southern Regional Centre, India
}

Submission: April 15, 2017; Published: April 28, 2017

*Corresponding author: K Govathi Nikhila, Ali Yavar Jung National Institute for the Hearing Handicapped, Southern Regional Centre, TRT-122/A,

Seethaphalmandi, Secundrabad, Telangana, 500061, India, Tel: 9582972948; Email: gnikhilaks@gmail.com

\section{Introduction}

Cleft lip and cleft palate, also known as oro-facial cleft. It may include cleft lip (CL), cleft palate (CP), and both together. Cleft lip and palate occurs due to the tissues of the face which are not properly joined together during the development of face and mouth. It is a type of birth defect. A cleft lip contains an opening in the upper lip that may extend into the nose. The opening may be on one side, or both the sides, or in the middle. A cleft palate is when the roof of the mouth contains an opening into the nose. These disorders can result in feeding problems, speech problems, hearing problems, and frequent ear infections. A cleft lip or palate can be successfully treated with surgery. This is often done in the first few months of life i.e. by 3months for cleft lip and before 18 months for cleft palate. Speech therapy and dental care may also be needed with appropriate treatment outcomes.

Cleft lip and palate occurs in about 1 to 2 per 1000 births in the developed world. Cleft lip is about twice as common in males as females, while Cleft palate without Cleft lip is more common in females. In 2013 it resulted in about 3,300 deaths globally down from 7,600 deaths in 1990. The condition was previously known as a hare-lip due to similarity to a rabbit, but that term is now generally considered to be offensive. When coming to the surgical treatment for cleft lip and palate children it was done very late in 1990's .In 1990's days as there was no much awareness about the surgical treatment on cleft lip and palate children most of the surgeries are done after the development of their speech and language. As their anatomical structure repaired very late, the child may tend to learn different error patterns due to their structural deformity and there are also studies in 1990's states that even children will compensate the error patterns even after the surgery and got cleared with the speech therapy. The error patterns normally the children with cleft lip and palate produce are as follows: a) Obligatory errors.

b) Misarticulations.

c) Compensatory articulation errors.

a) Obligatory errors: The sounds which are produced incorrectly before the surgical repair are known as obligatory errors. It is also known as "Passive errors". Common obligatory errors include hypernasality (too much nasal resonance), nasal emission, weak consonants, and short utterance length. Nasalized vowels, glides, liquids, and high vowels such as /i, u/ are susceptible to hypernasality errors. Nasal emissions most commonly affect sounds such as /s, z, sh, 3, ch, d3/. Obligatory errors can be corrected through surgery and through prosthetic intervention and these disappear after surgery [1].

b) Misarticulations: In children with cleft lip and palate they have sounds which most frequently misarticulated with VPI is /s/. As incompetence increase other sibilants and fricatives like (f, v, th, sh, z, zh) involved. The children with misarticulations they have weak consonants, and audible escape, but the placement is accurate.

c) Compensatory Errors: Children with a (repaired and unrepaired) cleft palate develop compensatory errors for reasons that are unknown. Usually, the structure has been repaired and the child is still trying to produce sounds using incorrect habits to "compensate" for previous structural deficiencies. These compensatory errors are typically when a child produces sounds farther back in the mouth than is appropriate. Common compensatory errors include (but are not limited to) glottal stops, pharyngeal fricatives, nasal fricatives, mid-dorsum palatal stops, and pharyngeal plosives.

Compensatory articulation pattern that occurs in individuals who have velopharyngeal dysfunction. The most common compensatory articulatory patterns are: 

a) Glottal stop
b) Pharyngeal stop
c) Pharyngeal fricative
d) Laryngeal fricative
e) Velar fricative
f) Mid-dorsum palatal stop
g) Posterior nasal fricative/nasal turbulence often accompanied by a nasal grimace.

So, from 1990's the children are followed by all these error patters. At present, as we are developed with new technologies and being more advanced, the surgical procedures are conducting very soon for the children born with the cleft lip and palate. The cleft lip was done before few months of their birth period (3-4 months) and palatal repair is done before 1.5yrs. Although the speech development starts before 1.5 yrs of their age, but it is still better when comparing it with the olden days. As they have anatomical deformity of their mouth they tend to produce the error patterns. As the anatomical structure is formed normally after the early surgical repair the child should learn the normal articulation patterns. But still we doesn't know that the children who are undergoing for earlier surgery are still compensating with their articulation errors or not because there are very less studies showing the effects of the age of surgery in relation to their compensatory errors [2].

Note: By taking all this into consideration, in the present study we would like to check the compensatory articulation patterns and their relation with the age of surgery in children with repaired cleft lip and palate.

\section{Review of Literature}

\section{Embriological development of Cleft Lip and Palate}

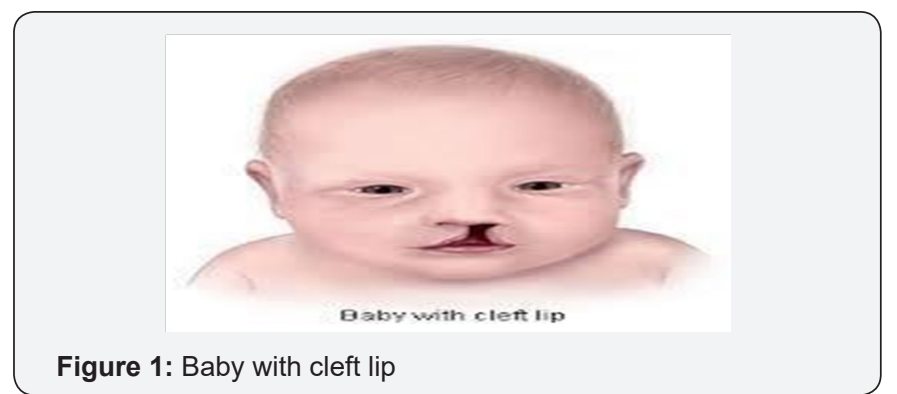

The formation of face takes place in the early stages of pregnancy and the special cells, body tissues are developed and join together to form a face. Later, this joining of the tissue forms the facial features like lip and mouth. By fourth and seventh weeks of pregnancy the development of lip takes place. If the lip anatomically does not form before birth then that is called as cleft lip and it results in an opening of the upper lip. The opening in the lip can be a small slit or it can be a large opening that goes through the lip into the nose. A cleft lip can be on one or both sides of the lip or in the middle of the lip, which occurs very rarely. Children with a cleft lip also can have a cleft palate (Figure 1) [3].



By sixth and ninth weeks of pregnancy the roof of the mouth (palate) is formed. If the tissue that makes up the roof of the mouth does not join together completely during pregnancy then there will be a slit formed in the palate and that is known as cleft palate. For some babies, both the front and back parts of the palate are open (Figure 2). For other babies, only part of the palate is open. There are various causes to explain why the cleft lip and palate is formed, for this reason most of the scientists believe that clefts are due to a combination of genetic and environmental factors. There appears to be a greater chance of clefting in a new born if a sibling, parent, or relative has had the problem [4].

Another potential cause may be related to a medication a mother may have taken during her pregnancy. Some drugs may cause cleft lip and cleft palate. Among them: anti-seizure/ anticonvulsant drugs, acne drugs containing Accutane, and methotrexate, a drug commonly used for treating cancer, arthritis, and psoriasis. Cleft lip and cleft palate may also occur as a result of exposure to viruses or chemicals while the foetus is developing in the womb.

\section{Problems associated with cleft lip and/or cleft palate}

a. Eating problems: With a separation or opening in the palate, food and liquids can pass from the mouth back through the nose. Fortunately, specially designed baby bottles and nipples that help keep fluids flowing downward toward the stomach are available. Children with a cleft palate may need to wear a man-made palate to help them eat properly and ensure that they are receiving adequate nutrition until surgical treatment is provided.

b. Ear infections and hearing loss: Children with cleft palate are at increased risk of ear infections since they are more prone to fluid build-up in the middle ear. If left untreated, ear infections can cause hearing loss. To prevent this from happening, children with cleft palate usually need special tubes placed in the eardrums to aid fluid drainage, and their hearing needs to be checked once a year.

c. Speech problems: Children with cleft lip or cleft palate may also have trouble speaking. These children's voices don't carry well, the voice may take on a nasal sound, and the 
speech may be difficult to understand. Not all children have these problems, and surgery may fix these problems entirely for some. For others, a special doctor called a speech pathologist will work with the child to resolve speech difficulties.

d. Dental problems: Children with clefts are more prone to a larger than average number of cavities and often have missing, extra, malformed, or displaced teeth requiring dental and orthodontic treatments. In addition, children with cleft palate often have an alveolar ridge defect. The alveolus is the bony upper gum that contains teeth. A defect in the alveolus can [5]

i. displace, tip, or rotate permanent teeth,

ii. prevent permanent teeth from appearing, and

iii. prevent the alveolar ridge from forming. These problems can be fixed through oral surgery.

iv. Can cause premature loss of erupting canines, and incisors.

\section{Normal articulation development}

Articulation refers to speech sound production. It is the way a sound is made using the mouth, tongue and vocal cords (voice box). Articulation includes all of the coordinated movements which result in speech sounds. Errors in articulation often result in speech sound errors. As children grow older, they learn to use more and more speech sounds that may have been difficult to pronounce in the fast. The following list includes approximate ages at which children normally develop the ability to produce specific speech sounds correctly (Figure 3) [6].

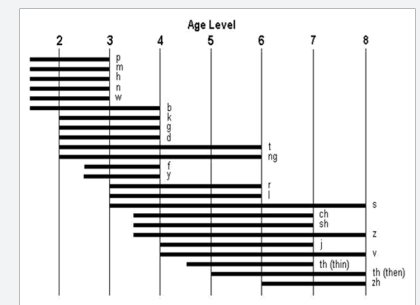

Figure 3: Sander Normal Articulation Development chart.

According to this chart the sounds like /p, m, h, n, w/ should be able to produce with the correct articulatory development by the age of 3 years and the sounds like /b, g. k ,d, f, y/ by the age of 4 years and the sounds like /t, ng, r, l/ by the age of 6 years and the sounds like /ch, sh, j, th/ by the age of 7 years and the sounds like $/ \mathrm{s}, \mathrm{z}, \mathrm{y}, \mathrm{th}, \mathrm{zh} / \mathrm{by}$ the age 8 years in the children with normal development. By the age of 8 years all the speech sounds are achieved completely. With reference to this normal developmental patterns in relation to their age criteria, it may differ in the children with cleft lip and palate due to their structural deformity. It depends on their development of anatomical structures and the surgical age.

All young children, when they are just learning to speak, mispronounce words. As they grow older and their articulation skills develop, their pronunciation usually becomes clearer. Most English-speaking children develop mature articulation skills and are able to pronounce all sounds accurately by about age 7 or 8. However, some children may exhibit inaccurate or distorted production of one or more sounds after age 7 or 8 , and may need speech therapy to correct these distortions.

\section{Articulation error patterns in children with Cleft Lip and Palate}

In children with cleft lip and palate they have different types of error patters they are
a) Misarticulations
b) Obligatory errors
c) Compensatory errors.

One common error pattern observed in speakers with repaired cleft palate is posterior placement of oral targets [7]. Different terms have been used to describe this error pattern, and there is some variation regarding what is included under this pattern. Gibbon and Crampin [8] referred to a "retracted or 'backed' tongue placement" which affects sibilants, alveolar stops, and velar stops. "Palatal misarticulations" is a pattern demonstrated via Electropalatography, which involves contact between the tongue dorsum/mid-dorsum and the hard palate [9]. "Backing" has been reported as a commonly occurring phonological process in children with cleft palate by several investigators [10] (Figure 4).

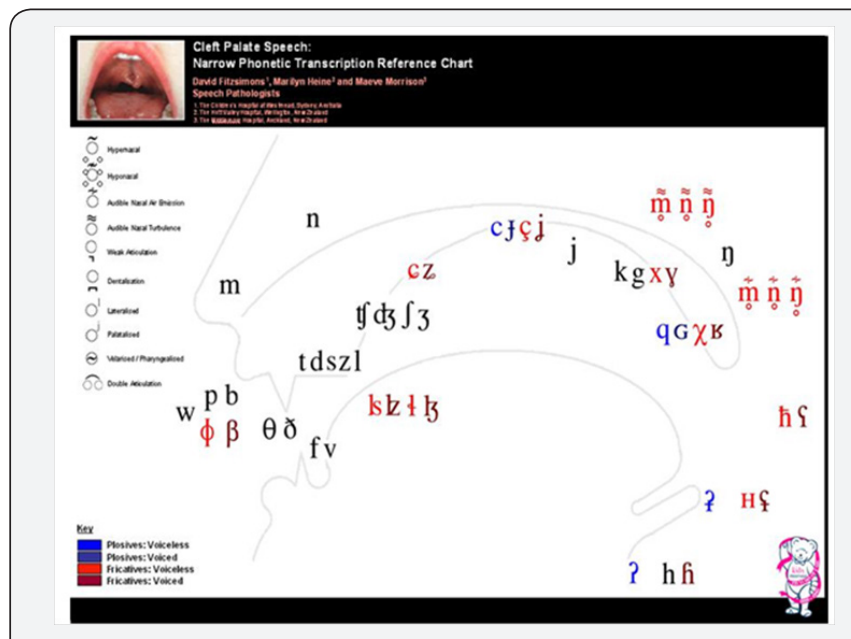

Figure 4: Error patterns in cleft palate children.

\section{Symbol Definition}

$\mathrm{h}$ - Voiceless pharyngeal central fricative.

S - Voiced pharyngeal fricative.

h - Voiced or murmured glottal fricative or approximate.

f - Voiceless fricative articulated with simultaneous velar and palate-alveolar friction.

щ - Voiced velar median (central) approximate. 
6 - Voiceless palatal central fricative. Articulated posterior to [S] (palate-alveolar) and [6] (alveolo-palatal) but not as far back as $[\mathrm{x}]$ (velar).

C - Voiceless alveolo-palatal central laminal fricative. Articulated between [c] (true palatal) and [S] (palate-alveolar).

Phonetic symbols that may be useful for the transcription of unusual articulations employed by some individuals with cleft palate [11]. The occurrence of dental consonant articulatory errors are higher among cleft patients than in non- cleft patients [12]. In children with cleft lip and palate they have sounds which mostly misarticulated with VPI is /s/. According to (Mc Williams) the children with cleft lip and palate have reduced intra -oral pressure when accompanied with VPI seems to accept their loss of intra- oral pressure and continued to articulate as accurately as possible. The children with misarticulations they have weak consonants and audible escape, but placement is accurate with slightly impaired intelligibility. As incompetence increases other sibilants' and fricatives like (f, v, th, sh, Z, s, zh) are involved [13]. Yamashita, Michik [11] examined the children with misarticulations who attained adequate VPI function and normal palatal valt at early surgical repairs by using Electropalatography (EPG) \& Sound Spectrography (SG), she found that the misarticulations are of 3 types, they are (palatalized, lateral, \& nasopharyngeal misarticulations) are there and these types are most common in cleft patients who have achieved adequate VPI function and normal palatal vault.

\section{Sounds most frequently misarticulated}

Mc Williams [6] and Spriestersbach et al. [14] described the articulation of heterogeneous groups of adults and children with palatal clefts. Consonants misarticulated more than $60 \%$ of the time by the children studied by Spriestersbach were /z/, /s/, /ts/, / $\theta /, / \mathrm{t} /, / \mathrm{d} /, / /, / \mathrm{s} /$. The consonants correctly articulated at least $80 \%$ of the times were $/ \mathrm{m} /, / \mathrm{h} /, / \mathrm{n} /, / \mathrm{j} /$, and $/ \mathrm{y} /$. In Williams study, shows the most frequently misarticulated sounds were /s/ (63\%), /z/ (61\%), /d/ (48\%), and /t / (44\%). Only $11 \%$ of $/ \mathrm{p} /$ sounds sampled and $9 \%$ of $/ \mathrm{b} /$ sounds were misarticulated. Van Demark et al. (1979) stated that most frequently misarticulated fricatives and affricatives, and /s/ had an especially low percentage of correct productions across the ages.

\section{Error types}

McWilliams $[6,10]$ found that, of 1814 misarticulated sounds produced by adult subjects with palatal clefts, 1436 were distortions, 335 were omissions, and 43 were substitutions. Mc Dermott [15] stated that most cleft palate speakers between 8 and 18 years of age produced distortions of $/ \mathrm{s} /$. He classified $70 \%$ of the /s/ sounds he studied as distortions, $23 \%$ as correctly articulated, $5 \%$ as omitted, and $1 \%$ as replaced by other sounds. Van Demark [16] observed from his study of cleft palate children between 5 and 14 years of age that nasal distortions were frequently produced. In spite of method differences, the findings of most studies are fairly consistent and suggest that children who receive early palatal repair demonstrate better overall speech than their peers who receive surgery at later age [17]."

There is also evidence to suggest that children who receive late palatal surgery are at greater risk for developing atypical patterns [18]. The vocal limitations of children with cleft lip and/ or palate prior to palate repair at (approximately 12months) do not seem surprising, studies indicate that these limitations often still exist for 1-3 years following repair. Additionally, these deficit are apparent regardless of cleft type rarely obstruction of the palate. Compensatory glottal productions are reported in the vocalizations of children prior to palate repair. These glottal productions often take the form of growls or "ohoh" productions and may become embedded into the early sound repertoire of the children with clefts. Scherer explored the relationship between word learning and speech sound repertoire in an intervention study. She found that young children with cleft lip and palate learned words with sounds that were within their consonant inventories faster than words with sounds that were outside their inventories.

Therefore, the children with cleft lip and palate used more words with nasals, glides, and glottals than words with oral consonants. Hardin-Jones and Jones examined the speech of 212 preschool and school aged children with cleft lip and palate. Approximately $13 \%$ of the children used nasal substitutions and $25 \%$ used compensatory articulation errors, specifically glottal stop substitutions. The findings indicate that these error patterns persist for a substantial number of children despite the fact that $68 \%$ of the children in this study had received speech therapy [19].

The compensatory errors during the (3-5) years often provokes the onset of speech therapy for many children with clefts. Studies have suggested that approximately $25 \%$ of children with clefts use compensatory articulation errors, and glottal stops appear to be the predominant error pattern. For children who use compensatory articulation patterns to a significant degree, speech intelligibility may be severely reduced. Further, when this pattern becomes habituated during the (3-5) years, it can be particularly resistant to change in therapy. Bardach et al. [20] reported that articulation was judged to be within normal limits for $57 \%$ of adolescents with bilateral cleft and palate. This is similar to the $55 \%$ reported by Peterson-Falzone [21] for adolescents with a variety of cleft types. Stoel- gummon \& Dunn, olson [22] states that who receive late palatal surgery are at greater risk for developing atypical patterns. curtain, [22], o'gara longemann, 1990 [23] did a study on CLP on their phonological development and stated that the Children with cleft lip and palate have compensatory patterns and also in un- repaired they have high $\%$ of backed compensatory articulation patterns.

There are few studies on the speech outcomes for palato plasty or secondary palatal management in patients who receive very late intervention. Sell and Grunwell [22], who evaluated the speech of 18 patients in Sri Lanka who underwent palate repair 
after the age of 11years. They found that speech production was usually severely impaired in patients with such late repair, and the postoperative results were variable and related to cleft type. Symptoms of hypernasality and nasal emission were improved with surgery, but there was little improvement in speech articulation when surgery alone was provided without speech therapy.

A study by Hall et al. evaluated the outcome of secondary palatal management in adults. These authors suggested that symptoms of hypernasality can be successfully eliminated in adults with cleft palate. One study in the literature describes two cases where in the speech in two bilingual children was near normal in their second language following pharyngeal flap surgery while they continued to demonstrate numerous articulation errors including compensatory articulation errors in their primary language. A major inference to be drawn is that the population of persons with cleft palate is highly heterogeneous in articulation; the speech pathologist may expect patients with cleft palate to vary widely in their articulation proficiency. Those who misarticulate will differ in the error patterns they present.

\section{Obligatory Errors}

Due to anatomical constraints, children with cleft lip and palate will be obligated to produce certain sounds incorrectly because it is structurally impossible for them to produce them with correct place and manner. It is also known as "obligatory/passive" errors. The common obligatory errors are hypernasality, nasal emission, \& weak consonant oral pressure obstruent's which can be attributed to VPI and / oronasal fistula and short utterances. Nasalized vowels, glides, liquids and high vowels such as /I, u/ are susceptible to hypernasality errors. Nasal emissions most commonly affects sounds such as /s, z, sh, $\mathrm{ch}, \mathrm{dz} /$. Obligatory errors can be corrected through prosthetic intervention.

\section{Normal place and manner of articulation with the production of sounds}

The sounds /p/, /b/ and /m/, for example, are produced with contact between the upper and lower lips, named bilabial sounds due to their place of production. The /f/ and /v/ are produced with approximation of the upper teeth and lower lip, named labiodental sounds. Sounds made with the tip or blade of the tongue are named coronal when the tongue articulates with the alveolar ridge (such as $/ \mathrm{s} /, / \mathrm{z} /, / \mathrm{l} /$ and $/ \mathrm{r} /$ ), and are named linguodental (such as $/ \mathrm{t} /, / \mathrm{d} /$ and $/ \mathrm{n} /$ ), when the tip of the tongue articulates with the teeth. Production of the velar sounds such as /k/, /g/ and /R/ involves contact or approximation of the back of the tongue to the back of the hard palate, while production of palatal sounds $/ \mathrm{s} /, / \zeta /, / \mathrm{y} /$ and $/ \lambda /$ involves contact of the middle part of the tongue and hard palate [24].

The consonants are also classified according to the manner of articulation, which refers to the type of constriction resulting from the articulatory contact. Thus, plosives sounds involve complete obstruction of the airstream followed by a sudden release that is heard as a plosion. Plosive sounds include /p/, /t/, /k/, /b/, /d/ and /g/. Fricative sounds are those involving a close approximation of the articulators, leading to an audible friction of the airstream, such as /f/, /s/, /s/, /v/, /z/ and / //. Affricate sounds involve both an obstruction followed by a constricted release of the airstream, such as /ts/ and /d $\zeta /$. Nasal sounds are the only ones produced with acoustic energy being displaced simultaneously to oral and nasal cavities, including $/ \mathrm{m} /, / \mathrm{n} /$ and $/ \mathrm{y} /$. Finally, a phoneme is called liquid when it is produced with a much wider passage of air compared to the narrow constriction observed for the fricatives. Liquid sounds includes $/ \mathrm{l} /, / \lambda /, / \mathrm{r} /$, and $/ \mathrm{R} /$. We can also name sounds according to pressure requirements into low-pressure sounds (like nasals and liquids) and high-pressure sounds (like plosive, fricative, and affricate).

\section{Compensatory Errors}

The behaviours which are thought to be learned and habituated for productions of speech sounds due to VPI, normal production cannot be achieved. Such type of behaviour of active nasal fricatives errors are known as "active/ compensatory errors" \& these are presumably developed as a learned attempt to compensate for physiological constraints; but may persist even after the initial repair of physiologic constraints. The literature suggests that individuals with CP and/or VPD often have difficulties producing consonants that require a high amount of intraoral air pressure, as plosives, fricatives, and affricates. According to Warren [19], the inability to generate and/or maintain adequate levels of intraoral pressure for production of plosion or friction may lead to the development of atypical places of production, called compensatory articulations (CAs). As described by Trost-Cardamone [25], when a CA is used, the manner is usually preserved, while the place of production is atypically posteriorized. Atypical place of production used for CA may involve the use of the pharynx (such as in the pharyngeal fricatives, posterior nasal fricatives, or pharyngeal plosives), the use of the glottis or larynx (such as in the glottal stops or laryngeal fricatives), or even oral but backed places of production (such as velar fricative and middorsum palatal stop).

The use of middorsum palatal stop (MDPS) is described in a literature for the plosives /t/, /d/, /k/ and /g/. The presence of VPD, or a palatal fistula, can explain some adjustment in tongue placement during speech, leading to compensations like the MDPS, for ex: - The tongue would move back towards a fistula, / for ex: - in an attempt to avoid air leakage during production of plosives / $t$ / and /d/, resulting in the use of the tongue dorsum in contact with the middle of the palate (MDPS). Children with a (repaired and unrepaired) cleft palate develop compensatory errors for reasons that are unknown. Usually, the structure has been repaired and the child is still trying to produce sounds using incorrect habits to "compensate" for previous structural deficiencies. These compensatory errors are typically when a child produces sounds farther back in the mouth than is appropriate. Common compensatory errors include "glottal 


\section{Global Journal of Otolaryngology}

stops, pharyngeal fricatives, nasal fricatives, middorsum palatal stops, and pharyngeal plosives". Kummer [26] gave a common compensatory articulation errors as follows:

a) Glottal stop substitution: The true and false vocal folds adduct as a substitute for blocking the airflow of the vocal tract.

b) Pharyngeal fricatives: Producing a fricative sound in the throat with the root of the tongue instead of in the mouth with the front of the tongue.

c) Nasal fricative: Snorting air through the nose while producing a fricative.

d) Mid-dorsum palatal stops: Airflow is occluded by the dorsum of the tongue to produce a stop consonant.

e) Pharyngeal plosives: The tongue moves posteriorly to meet the pharyngeal wall or the walls of the pharynx move inward toward to meet the tongue. Air then quickly flows through the limited airway to produce this sound.

f) Nasalized / $/$ / (ng / r Substitution or Incorrect $/ \mathbf{r} /$ ): As $/ \mathrm{r} /$ sound production is attempted, the entire back of the tongue is raised (instead of only touching the sides of the tongue to the inside of the molars), then the $/ \mathrm{r} /$ sound will become the "ng" sound, resulting in nasal resonance (Table 1). Warren [25] postulated that compensatory speech behaviours used by patients with clefts are manifestations of a physiological regulation control mechanism that serves to maintain a normal aerodynamic environment even though the velopharyngeal mechanism is disabled.

Table 1: Representing the compensatory errors and their substitutions.

\begin{tabular}{|c|c|}
\hline Compensatory Misarticulations & Commonly Substituted For \\
\hline & $\begin{array}{l}\text { Stop Consonants (or any high } \\
\text { pressure consonants) }\end{array}$ \\
\hline Glottal Stop & Substitution for / k/ and /g/ \\
\hline Pharyngeal Stop & $\begin{array}{l}\text { Substitution for sibilant fricatives } \\
/ \mathrm{s} / / \mathrm{z} / / \mathrm{S} / / \mathrm{z} / \text { or for oral } \\
\text { affricates } / \mathrm{t} \int / / \mathrm{d} /\end{array}$ \\
\hline Pharyngeal Fricative & $\begin{array}{l}\text { Substituted for oral affricates / } \\
\qquad \mathrm{t} / / / \mathrm{d} /\end{array}$ \\
\hline Pharyngeal Affricate & $\begin{array}{l}\text { Substituted for sibilant fricatives } \\
\text { and affricates }\end{array}$ \\
\hline $\begin{array}{l}\text { Posterior Nasal Fricative } \\
\text { "snorting" }\end{array}$ & $\begin{array}{l}\text { Substituted for sibilant fricatives } \\
\text { or any of the stop consonants }\end{array}$ \\
\hline \multicolumn{2}{|c|}{ Nasal Fricative } \\
\hline $\begin{array}{l}\text { Mid- Dorsum Palatal Stop (sounds } \\
\text { like a mix between } / \mathrm{t}-\mathrm{k} / \text { or/d-g/) }\end{array}$ & $\begin{array}{c}\text { Substituted for } / \mathrm{t} / \text { or } / \mathrm{k} / \text { and } / \mathrm{d} / \\
\text { or } / \mathrm{g} /\end{array}$ \\
\hline \multicolumn{2}{|c|}{ Backed Oral Productions } \\
\hline $\begin{array}{l}\text { Mid Dorsum Palatal Fricative } \\
\text { (sounds like a cat hiss) }\end{array}$ & Velar fricative \\
\hline \multicolumn{2}{|c|}{ Substituted For } \\
\hline \multicolumn{2}{|l|}{ Sibilant fricatives and affricates } \\
\hline $\begin{array}{l}\text { Sibilant fricatives sometimes } \\
\text { affricates }\end{array}$ & \\
\hline
\end{tabular}

Jonees; chapman and Hardin Jones [27] they did a study on 28 children among which 14 children with cleft palate and 14 without cleft matched for age, gender. He compaired the children with cleft palate before and after the surgery of consonant inventories; place and manner characteristics and early developing sounds ( $p, b, t, d, g, m, n$, etc.) and it is compaired with the clefts at post-surgery (17 months) children. The results revealed that paired $t$ tests were performed in preand post-surgery of the children with cleft palate. Although no significant differences were noted for place and manner features, production of oral stops doubled from the time before surgery to that after surgery.

Specifically, production of the bilabial stop [b] showed significant change over time with no differences at 17 months. However, significant group difference were noted for production of stops; oral stops; nasals; glides and alveolar. The children without clefts produced more stops; oral stops and alveolar. In contrast more nasals and glides were seen in the vocalizations of children with cleft palate. James 2002 [28] did a study on 129 individuals with repaired cleft of lip and or palate above the age of 3 years from a district in south India; revealed that 38\% had normal and age appropriate communication skills. The majority of those with normal communication skills had isolated cleft of lip. $43 \%$ of children exhibited abnormalities in articulation and resonance, $12 \%$ had only articulation deviations and $3 \%$ only abnormalities in resonance and another $3 \%$ of these individuals exhibited delay in language development.

Chapman 2003 did a study and examined the relationship between pre-surgery speech measures and speech and language performance at 39 months as well as the relationship between early post-surgery speech measures and speech and language performance at 39 months of age. Fifteen children with cleft lip and palate participated in the study. Spontaneous speech samples were obtained in the children's homes at pre surgery /9 months, post-surgery/13 months and again at 39 months of age. Correlational analyses revealed a lack of association between speech measures presurgery and early post-surgery and speech outcome measures at 39 months. Significant negative correlations were noted for true canonical babbling ratio presurgery and mean length of utterance (MLU) at 39 months, as well as for size of true consonant inventory presurgery, and both language outcome measures at 39 months (MLU and number of different words). Significant positive correlations were noted for percentage of true stops produced post-surgery and both language measures at 39 months. Variables that may have influenced speech and language development from presurgery to 39 months are discussed [29].

Rullo, Addabbo, Rullo, Festa, Perillo [30] did a study on resonance and articulation disorders and were examined in a group of patients surgically treated for cleft lip and palate, Fifty children (32 males and 18 females) mean age $6.5 \pm 1.6$ years, affected by non-syndromic complete unilateral cleft of the lip and palate underwent the same surgical protocol. The speech 
level was evaluated and focused on intelligibility, nasality, nasal air escape, pharyngeal friction, and glottal stop. A total of $16 \%$ ( 8 children) of the sample had severe to moderate degree of nasality and nasal air escape, presence of pharyngeal friction and glottal stop, which obviously compromise speech intelligibility. Ten children (10\%) showed a barely acceptable phonological outcome: nasality and nasal air escape were mild to moderate, but the intelligibility remained poor. Thirty-two children (64\%) had normal speech. Statistical analysis revealed a significant correlation between the severity of nasal resonance and nasal air escape $(\mathrm{p} \leq 0.05)$.

Cohn and Williams [31] gathered articulation data on 204 children with clefts, among which 105 children with UC had pharyngeal misarticulations, and only $1 /<1$ had glottal stops. 7 of 109 subjects $(6 \%)$ with isolated palate cleft had pharyngeal errors, and only $5(4.5 \%)$ had glottal errors. In entire group only 1 has nasal snort. These children had surgical closure of their palates by 18 months of their age, and none of them had rated with severe hypernasality. Trost [32] described 3 types of compensatory articulation and these added to the list of articulation patterns characteristic of individuals with cleft palate / other velopharyngeal valving faults. Her observations were based on auditory perception and the use of cephalometric radiographic studies.

a) $1^{\text {st: }}$ The substitution of pharyngeal stop for $/ \mathrm{k} /$ and $/ \mathrm{g} /$.

b) $2^{\text {nd: }}$ Mid-dorsum palatal stop, which is similar in vocal tract location of $/ \mathrm{j} /$, when used it is substituted for $/ \mathrm{t} /, / \mathrm{d} /$,/ $\mathrm{k} /$,or/g/. The distinction between the voiced and voiceless members of cognate pairs replaced by the mid-dorsum palatal stop is lost, thus making phonemic distinctiveness dependent upon non-segmental cues.

c) $3^{\text {rd: }}$ Lingualveolar nasal fricatives produced with an open/incompletely closed velopharyngeal port, accompanied by nasal emission, and distinctive because of audible frication.

Trost and also Henningsson and Isberg [33] noted that some speakers with clefts uses two places of articulation simultaneously. ex:- some individual make tongue tip gestures for /t/ while producing glottal stops. Only glottal stops and pharyngeal fricatives were found by Trost to co- occur with normal articulatory placement. Distinctions among these sounds would be difficult to make without radiographic analysis. Kawano et al. [10] descried a 20 yrs old Japanese cleft lip and palate who replaced /s/ and / / with an unusual laryngeal fricative. This patient had not undergone palato plasty until he was 8 yrs of age.

Fletcher [16] descried a patient with an unrepaired cleft of the soft palate and of approximately $28 \mathrm{~mm}$ of the hard palate. The cleft was $18 \mathrm{~mm}$ wide at the posterior border of the hard palate .This man's total phoneme intelligibility was $79 \%$ and
91\% of his /s/ sounds were intelligible. Electropalatography indicated that this speaker narrowed the constriction for sibilant fricatives .ex:- “.... /s/ in seed was spoken with a groove only 2$3 \mathrm{~mm}$ wide." Normal talkers used a groove $6-10 \mathrm{~mm}$ wide.

Henningsson \& Isberg [26] determine that velopharyngeal closure is impaired - particularly movement of the lateral pharyngeal walls is reduced -during glottal stops and cooccurrence of glottal stops and other articulatory gestures. They concluded that velopharyngeal openings during these sounds may give a false impression of inability to close the velopharyngeal port. If closure is present during other speech sounds, velopharyngeal function during glottal stops should be observed for change during the course of articulation therapy directed to the correction of the glottal stops. Hutters \& Brondsted [10] reported the result of narrow phonetic transcription of the speech of 5 Danish children ranging in age from 4.2-5.2. The children presented palatal clefting ranging from cleft of the palate only to BCLP. The speech patterns identified were classified according to 3 strategies to be summarized below.

i. 1st: child was characterised by use of glottal stops for stops and fricatives, and both progressive and regressive assimilation were noted.

ii. 2nd: child also used glottal stops mostly for stop consonants. The glottal stops were produced in combination with the correct supra-glottal articulatory gestures.

iii. 3rd: child produced stop correctly, but also replaced stops with voiced nasal consonants and with voiceless nasal fricatives. Fricatives were variably produced but often involved nasal frication.

iv. 4th: child tend to replace stops and fricatives with nasal consonants or [h]. Glottal stops were also observed. This child's speech was said to be "frequently interrupted by superficial snatching of breath."

v. 5th: child misarticulated relatively few sounds. However, they replaced the velar $(/ \mathrm{k} /$ and $/ \mathrm{g} /$ with $/ \mathrm{h} /$ and partially devoiced $\left[\mathrm{d}_{l}\right]$ and fronted $[\mathrm{g}<]$. The speech of these children was characterised by reduced accuracy and reduced number of phonemes.

Bzoch (1979) [11] observed the chareteristics in 1000 cleft palate patients, included laryngeal and pharyngeal substitution errors, consonant distortions from audible nasal emission, lisping, and other articulation distortions associated with hearing loss. Developmental misarticulations and delayed speech and language development were observed, and some patients had facial grimaces that interfered with communication.

\section{Surgical Procedures}

The surgical procedures required for each patient with cleft lip and palate will vary depending upon the type and severity of the deformity. Timing and treatment will be adjusted based 
on each patient's overall medical needs, but treatment typically includes a combination of the procedures explained here, performed within general time frames based on development.

\section{Early Surgery}

a. Cleft Lip Repair (3 to 6 months): The cleft lip surgery is to repair the separation of the lip. Cleft lip is typically repaired between 3 and 6 months of age. During those first few months, the child is monitored closely for adequate weight gain and nutrition, and to make sure that there are no issues relative to breathing while eating. There are a variety of techniques that may be used to repair a cleft lip. The most common type of cleft lip repair is a rotation advancement repair.

b. Cleft Palate Repair ( 9 to 18 months): The cleft palate surgery is to fix the roof of the mouth so that the child can eat and talk normally. Cleft palate repair is a more complicated surgery and has the best outcome when the child is slightly older and better able to tolerate the surgery, but before significant speech development occurs. Surgical repair of the palate generally occurs around 1 year of age, following the successful repair of cleft lip if present. In some cases, a second operation is needed.

Palate repair closes these layers while also realigning the palatal muscles, a procedure called an intravelar veloplasty. This puts the muscles in a normal position that allows for the best function of the palate during speech, eating and swallowing. Surgical repair of cleft palate separates the oral and nasal cavities. This separation involves the formation of a watertight and airtight valve that is necessary for normal speech. The repair also helps with preserving facial growth and proper dental development. Once the lip and palate are repaired, typically no further surgery is performed for several years. A portion of the palate is usually left open to allow room for the mouth, palate and jaw to grow.

The age of acquisition of sound patterns \& compensatory articulation errors may depend up on the age of surgery i.e. , Earlier the surgery before 3 months of age may give you a result of less compensatory errors when comparing with the later surgery I.e., after acquisition of language development. The optimum age for surgical age closure of cleft palate remains an unresolved question, despite the fact that many clinicians have studied the issue since the 1930's \& the surgery is mostly done after the language development in those days .so, there are many compensatory errors, hypernasality, insufficient VP function, and as there is a lack of speech therapy they may tend to compensate the errors even after the surgical repair.

The primary purpose of cleft palate repair is to provide an intact mechanism for normal speech production. The speech problems include not only hypernasality but also highly unusual misarticulations of consonants. The hypernasality of vowels and nasal air emissions on consonants may be surgically remedied by means of pharyngoplasty; and the misarticulations of consonants related to a cleft palate can require years of intensive speech therapy. Surgical literature has indicated that the palate should be repaired between 18 \& 24 months of age \& current developmental research has shown that speech develops before $18 \& 24$ months of age. The consonants vowel sequences emerge between $6 \& 9$ months in normal\& the misarticulations of consonants that have been observed in youngster and adults with repaired cleft palate.

This process is developing prior to surgical reconstruction and persisting post operatively. It has been speculated that these articulatory abnormalities might be reduced if palatal reconstruction were completed at an earlier age (4-6 months) [12]. Chapman; Hardin $[6,25]$ did a study on their relationship between early speech and later speech and language performance on children with cleft lip and palate at pre surgery (9 months) and post-surgery (13 months) and speech and language performance at 21 months and also compaired this with normal. They suggested that true stop production is immediately before and after palatal surgery, were positively correlated with a majority of the speech production measures at 21 months.

At post-surgery (13 months) true stop production was related to later vocabulary development and size of true consonant inventory was related to all measure of speech production and one measure of lexical development at 21 months. For the normal peers group, true canonical babbling ratio at 13 months was the only measure that was significantly correlated with any of the speech and language measures at 21 months. Even with early surgical repair, a majority of pre-schoolers demonstrate delays in speech sound development and have typical cleft palate speech.

Late Surgery: In a Thomas 2001 literature it shows a evidence that the children who have underwent palatal closure before 6 months are less effected with their articulation errors when compaired with later 6 months. Later various authors stoel-gummon \& dunn 1985; olson 1965 states that who receive late palatal surgery are at greater risk for developing atypical patterns like VPI; Active fricatives errors, hypernasality. Morley [14] described 2 speech patterns in cleft palate patients who had palatal surgery after speech development (6-8 yrs.)

a) 1st - pattern involved good place of articulation and intelligible speech in association with nasal emission and consonants weakness resulting from lack of intra-oral breath pressure.

b) 2nd - pattern involves not only nasal escape, but also nasal snort, glottal stops, pharyngeal fricatives, nasal grimace, and other articulatory substitutions.

Again Albert et al. [6] presented the speech outcomes in children who undergone surgery from (6-15 years) and they have consonant production errors, hypernasality, nasal emissions and / turbulence. Michael Mars, William [23] investigates the effects of surgery on children with cleft lip and palate who have underwent for palatal surgery after 13 years and concluded that 
children who have underwent for repair in earlier infancy shows relatively better with the articulation when compaired with the later surgery. Here, by there are no much evidence showing the impact of age of surgery with their compensatory errors. Morley [24] described 2 speech patterns found in patients with cleft palate who had palatal surgery after speech development. One pattern involved good place of articulation and intelligible speech in association with nasal emission and consonant weakness resulting from lack of intraoral breath pressure. The second pattern involved not only nasal escape, but also nasal snort, glottal stops, pharyngeal fricatives, nasal grimace, and other articulatory substitutions

\section{Summary}

In summary, compensatory articulation errors in children with cleft lip and palate have been well- documented. Several explanations have been offered for these patterns, but there is little evidence to support any of the explanations. Most explanations have focused on physiological factors; such as velopharyngeal incompetence. However, there have been few investigations on compensatory articulation errors of children with cleft lip and palate. Such an investigation could contribute to our understanding of the impact of surgery on compensatory articulation errors on this group of children. So, in the present study we would see the impact of compensatory errors on the age of surgery.

\section{Need of the Study}

a) Various authors, stoel- gummon \& Dunn [22], olson [26], states that who receive late palatal surgery are at greater risk for developing atypical patterns.

b) Curtain, o'gara longemann, [25] did a study on CLP on their phonological development and stated that the Children with cleft lip and palate have compensatory patterns and also in un- repaired they have high \% of backed compensatory articulation patterns.

c) From the above two evidences, the studies quoted have tried to show their behaviors.

d) This study will help us to understand the compensatory errors or Articulatory Development with the contribution of age of surgery in children with cleft lip and palate.

\section{Aim}

The aim of the study is to ascertain the impact of the compensatory articulation errors in relation to the age of surgery in children with repaired cleft lip and palate.

\section{Hypothesis}

There may not be any difference in the compensatory patterns in children with repaired cleft lip and palate in relation to their age of surgery.

\section{Objectives}

To analyse the speech of the children with repaired cleft lip and palate and also analyse the function of age of surgery with their errors.

\section{Methodology}

The review of literature, as presented in the previous chapter has shown that the study of compensatory errors and the surgeries in Telugu language in children with early and late palatal surgery. Therefore, the present study was designed to investigate the impact of age of surgery on the compensatory errors in Telugu native speaking children in subjects with repaired cleft lip and palate (Table 2).

Table 2: Shows about the total number of subjects with their type of cleft and age of surgery.

\begin{tabular}{|c|c|c|c|}
\hline \multicolumn{4}{|c|}{ Bilateral Cleft Lip And Palate } \\
\hline Group-1 Early Palatal Surgery & Group-2 Late Palatal Surgery \\
\hline Present Age & Age of Surgery & Present Age & Age of Surgery \\
\hline 7-15 Years. & Before 2 years. & 7-19 years & After 2 years. \\
\hline Total & 20 Subjects & Total & 20 Subjects \\
\hline
\end{tabular}

\section{Subjects}

Two groups of forty Telugu native speakers were participated in the study. Two groups are with congenital bilateral cleft lip and palate. The two groups was divided accordingly with their age of surgery. The each group is divided with equal population and they are named as GROUP-1 and GROUP-2.

a) Group-1 consists of 20 children, their present age is considered from (7-15 years) with mean (11.95 years). In this it consists of subjects with Early cleft repaired I.e., before 2years with mean ( 1.87 years).

b) Group-2 consists of 20 children, their present age is considered from (7-19 years) with mean (14.5 years). In this it consists of subjects with late cleft repaired i.e. after 2 years till 4 years with mean (3.95 years) were considered in this study. Later these two groups are considered \& divided accordingly with their age at which the surgery was done and also with their chronological age.

Subjects with repaired cleft lip and palate were taken from the "GSR Institute of Craniofacial cleft surgery".

GROUP-1 will be of 20 patients and GROUP-2 will be of 20 patients accordingly with their chronological age along with their surgical age and their errors. All subjects are Telugu speaking children. They were having no history of congenital anomalies, neurological impairment, sensorineural hearing impairment or intellectual deficits. All the variables were controlled as far as possible. Children having adequate language were included in this study.

a) The GROUP -1 Patients with Early repaired are checked with their compensatory errors and again further it is also 
checked whether the child is attending speech therapy or not with respect to their surgical age. The mean age for Early palatal surgery was (1.87years) in this group from 4 months to 2 years.

b) Then in GROUP-2 children with late repair of cleft are also followed with the same as GROUP - 1. The mean age for late palatal surgery was (3. 95years) with a range from 2-4 years. It is also cross checked that whether the cleft is partial or complete in the children's with bilateral cleft lip and palate. The age group was considered from birth to the surgery time \& the compensatory errors are checked accordingly in early repaired and Late repaired group children.

Later, it is also cross checked that whether the child is attending the speech therapy / not. Accordingly the test is done separately on each individual child.

\section{Selection Criteria}

Subjects from these groups were selected based on the following inclusion criteria:

a) All children should be with repaired bilateral cleft lip and palate.

b) Should not have any voice problems and any other associated problems like visual inacuity, mental retardation, any syndromes.

c) Should have hearing levels of $30 \mathrm{~dB}$ or better.

d) Should have Telugu as mother tongue.

e) Should have normal IQ.

\section{Tools \& Procedure}

TTAP-Telugu test of Articulation and phonology": Th "Telugu Test of articulation and phonology (TTAP) developed by Vasanta D [10] was used as a tool in this study. The test consists of 100 words with the picture representation and \& some are nonposturized. The words in this test are classified into categories like stops, affricates, fricatives, laterals/trills, semivowels and clusters. The test terms used in test as /e: nugu/, /kappa/, /sp: $\mathrm{nu} /$, /brassu/, etc.

\section{Audio-Recording Procedure}

The recording was carried out in the sound treated room of the institute. Each subject was seated in comfortable chair in sound -isolated roam. For eliciting the response, picture cards and real objects and toys were used. The clinician had an informal interaction with all the subjects and build rapport before testing to elicit the response. All the subjects were individually tested. The target words were elicited by the examiner by showing the pictures and the subject is asked to repeat the same targeted word by seeing the picture. The subject is shown with an each individual picture for a targeted sound and that particular word is produced only for once and not allowed for any corrections again or any repetitions of same word for twice. For this purpose a Audio recording is done in Samsung recorder with unidirectional microphone.

Instruction: The subject were instructed to repeat or follow the researcher who is repeating the 100 standardized telugu words , and the subject should see the picture and hearing to the targeted sound and repeat it immediately along with the examiner. Each subject was seated in a comfortable chair in a sound -isolated room. The subject was then asked to repeat the examiner's model of 100 single words one after the other. For which a audio recording is done. Here, there are two groups with early and late palatal surgical repair and they were analyzed separately.

\section{Audio- Data Analysis}

In this the client responses were audio recorded. IPA Transcription was used for data analysis. By using the IPA transcription, the error analysis was done in the children with cleft lip and palate to come up with the type of error pattern. In this most of the sounds are analyzed by using IPA Transcription but few sounds like pharyngeal fricatives, pharyngeal stops, mid-dorsum fricative stops, and mid-dorsum palatal fricatives are not. According to Yamashita \& Michik they stated that to analyze those sounds there is a need of objective measurements like Electropalatography (EPG) \& Sound Spectrograph (SG), in need and they also come up with few results on those sounds . Based on those results \& comparisions the analysis was done on those particular sounds. Data for each age group was analyzed separately. The mean percentage of occurrence for each compensatory error was computed by dividing the total number of opportunities for the occurrence of the process. A significant percentage was taken to show the comparison between two different groups and it also showed that a significant better results in the children with early palatal surgery than with the late palatal surgery.

\section{Results}

The purpose of the present study was to check the impact of compensatory errors in relation to the age of surgery in children with repaired cleft lip and palate with their surgical age ranging from 4 months to 4 years. The study reveals the following findings of compensatory errors in relation to its age of palatal surgery within 2 groups, GROUP-1 (4MONTHS -2 YEARS) and GROUP -2 (2 YEARS - 4YEARS). The results have been discussed in terms of within group and also group comparison of compensatory errors scores across repaired cleft lip and palate between Early and Late Palatal surgeries. As there are several variables, each particular variable is analyzed and given with the mean percentage.

\section{Group-1 Early Palatal Surgery}

The results in the Early palatal repair indicate that the compensatory errors in early palatal surgery scores Was $20 \%$ of (G.S, P.S, PNA) ,45\% of (P.F), 55\% of (N.E), 30\% of (N.F,M-H), $15 \%$ of (P.B), AND $5 \%$ of (V.F,C.R). This can be observed in the 


\section{Global Journal of Otolaryngology}

(Table 3) (Figure 5).

Table 3: Represents the mean percentage of the compensatory errors in children with early palatal surgery.

\begin{tabular}{|c|c|c|}
\hline Sl. no & $\begin{array}{c}\text { Compensatory } \\
\text { errors }\end{array}$ & Early palatopalsty \\
\hline 1 & $\begin{array}{l}\text { Glottal stops } \\
\text { (G.S) }\end{array}$ & $20 \%$ \\
\hline 2 & $\begin{array}{c}\text { Pharyngeal stops } \\
\text { (P.S) }\end{array}$ & $20 \%$ \\
\hline 3 & $\begin{array}{c}\text { Pharyngeal fricatives } \\
\text { (P.F) }\end{array}$ & $45 \%$ \\
\hline 4 & $\begin{array}{c}\text { Pharyngeal affricates } \\
\text { (P.A) }\end{array}$ & $0 \%$ \\
\hline 5 & $\begin{array}{l}\text { Pharyngeal Backing } \\
\text { ( P.B) }\end{array}$ & $15 \%$ \\
\hline 6 & $\begin{array}{l}\text { Posterior Nasal } \\
\text { affricates (PNA) }\end{array}$ & $20 \%$ \\
\hline 7 & $\begin{array}{c}\text { Nasal fricatives } \\
\text { (N.F) }\end{array}$ & $30 \%$ \\
\hline 8 & $\begin{array}{c}\text { Nasal Emissions } \\
\text { (N.E) }\end{array}$ & $55 \%$ \\
\hline 9 & $\begin{array}{l}\text { Mid Dorsum fricative } \\
\text { stops (MDFS) }\end{array}$ & $0 \%$ \\
\hline 10 & $\begin{array}{l}\text { Mid Dorsum palatal } \\
\text { fricatives (MDPF) }\end{array}$ & $0 \%$ \\
\hline 11 & $\begin{array}{r}\text { Velar fronting } \\
\text { (V.F) }\end{array}$ & $5 \%$ \\
\hline 12 & $\begin{array}{r}\text { Velar palatal } \\
\text { (V.P) }\end{array}$ & $0 \%$ \\
\hline 13 & $\begin{array}{c}\text { Cluster reduction } \\
\text { (C.R) }\end{array}$ & $5 \%$ \\
\hline 14 & $\begin{array}{l}\text { Mild hypernasality ( } \\
\text { M-H) }\end{array}$ & $5 \%$ \\
\hline
\end{tabular}

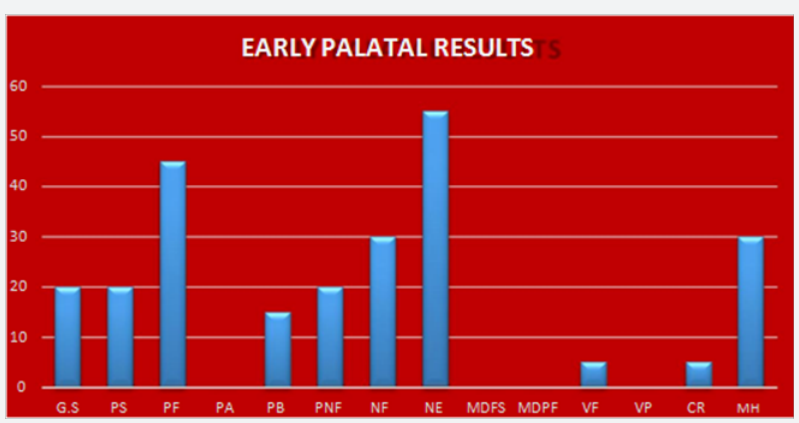

Figure 5: Represent the severity of the compensatory errors in percentage in children who have undergone for Early palatal surgery.

\section{Group-2 Late Palatal Surgery}

The results in the Late palatal surgery was $5 \%$ of (P.A), $10 \%$ of (G.S,V.F), $15 \%$ of (C.R), $20 \%$ of (V.P), 30\% of (MDFS), 35\% of (P.B) , $45 \%$ of (N.F), $50 \%$ of (P.S), $55 \%$ of (M-H), $60 \%$ of (PNA, N.E), and $70 \%$ of (P.F).This can be observed in the (Table 4 and Figure 6).
Table 4: Represents the mean percentage of the compensatory errors in children with Late palatal surgery.

\begin{tabular}{|c|c|c|}
\hline Sl.no & Compensatory errors & $\begin{array}{c}\text { Late } \\
\text { palatoplasty }\end{array}$ \\
\hline 1 & Glottal stops ( G.S) & $10 \%$ \\
\hline 2 & Pharyngeal stops ( P.S) & $50 \%$ \\
\hline 3 & $\begin{array}{c}\text { Pharyngeal fricatives } \\
\text { (P.F) }\end{array}$ & $70 \%$ \\
\hline 4 & $\begin{array}{c}\text { Pharyngeal affricates } \\
\text { (P.A) }\end{array}$ & $5 \%$ \\
\hline 5 & Pharyngeal Backing & $35 \%$ \\
\hline 6 & $\begin{array}{l}\text { Posterior Nasal affricates } \\
\text { (PNA) }\end{array}$ & $60 \%$ \\
\hline 7 & $\begin{array}{l}\text { Nasal fricatives } \\
\text { (N.F) }\end{array}$ & $45 \%$ \\
\hline 8 & Nasal Emissions (N.E) & $60 \%$ \\
\hline 9 & $\begin{array}{l}\text { Mid Dorsum fricative stops } \\
\text { (MDFS) }\end{array}$ & $30 \%$ \\
\hline 10 & Mid Dorsum palatal fricatives & $0 \%$ \\
\hline 11 & $\begin{array}{l}\text { Velar fronting } \\
\text { (V.F) }\end{array}$ & $10 \%$ \\
\hline 12 & $\begin{array}{l}\text { Velar palatal } \\
\text { (V.P) }\end{array}$ & $20 \%$ \\
\hline 13 & $\begin{array}{c}\text { Cluster reduction } \\
\text { (C.R) }\end{array}$ & $15 \%$ \\
\hline 14 & Mild hypernasality (M-H) & $55 \%$ \\
\hline
\end{tabular}

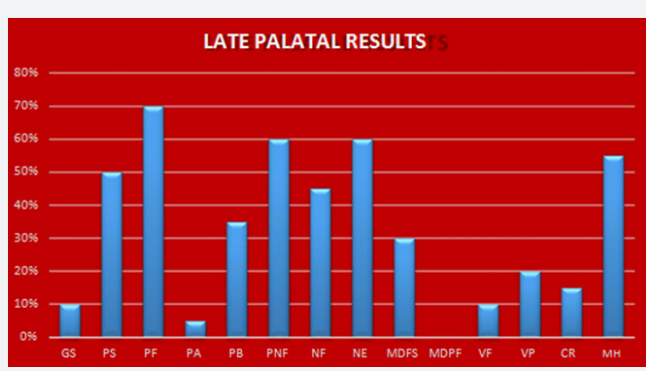

Figure 6: Represent the severity of the compensatory errors in percentage in children who have undergone for Late palatal surgery. 


\section{Comparison of 2 Groups Early Vs. Late Surgery (Table 5) (Figure 7)}

Table 5: Represents the mean percentage of compensatory errors in both the group children with cleft lip and palate

\begin{tabular}{|c|c|c|c|}
\hline Sl.no & Compensatory errors & Early palatopalsty & Late palatoplasty \\
\hline 1 & $\begin{array}{l}\text { Glottal stops } \\
\text { ( G.S) }\end{array}$ & $20 \%$ & $10 \%$ \\
\hline 2 & Pharyngeal stops ( P.S) & $20 \%$ & $50 \%$ \\
\hline 3 & $\begin{array}{c}\text { Pharyngeal fricatives } \\
\text { (P.F) }\end{array}$ & $45 \%$ & $70 \%$ \\
\hline 4 & $\begin{array}{l}\text { Pharyngeal affricates } \\
\text { (P.A) }\end{array}$ & $0 \%$ & $5 \%$ \\
\hline 5 & $\begin{array}{l}\text { Pharyngeal Backing } \\
\text { (P.B) }\end{array}$ & $15 \%$ & $35 \%$ \\
\hline 6 & $\begin{array}{c}\text { Posterior Nasal affricates (PNA) } \\
20 \%\end{array}$ & $60 \%$ & \\
\hline 7 & $\begin{array}{l}\text { Nasal fricatives } \\
\qquad \text { (N.F) }\end{array}$ & $30 \%$ & $45 \%$ \\
\hline 8 & $\begin{array}{l}\text { Nasal Emissions } \\
\qquad(\mathrm{N})\end{array}$ & $55 \%$ & $60 \%$ \\
\hline 9 & $\begin{array}{l}\text { Mid Dorsum fricative stops } \\
\text { (MDFS) }\end{array}$ & $0 \%$ & $30 \%$ \\
\hline 10 & $\begin{array}{l}\text { Mid Dorsum palatal fricatives } \\
\qquad \text { (MDPF) }\end{array}$ & $0 \%$ & $0 \%$ \\
\hline 11 & $\begin{array}{l}\text { Velar fronting } \\
\text { (V.F) }\end{array}$ & $5 \%$ & $10 \%$ \\
\hline 12 & $\begin{array}{l}\text { Velar palatal } \\
\qquad \text { (V.P) }\end{array}$ & $0 \%$ & $20 \%$ \\
\hline 13 & $\begin{array}{l}\text { Cluster reduction } \\
\qquad(\mathrm{C} . \mathrm{R})\end{array}$ & $5 \%$ & $15 \%$ \\
\hline 14 & $\begin{array}{l}\text { Mild hypernasality } \\
\qquad(\mathrm{M}-\mathrm{H})\end{array}$ & $30 \%$ & $55 \%$ \\
\hline
\end{tabular}

Here from the above graph the Blue region is of children who have undergone with the early palatal repair and their percentage of errors and the Red region is the children who have undergone with the late palatal surgery and their errors with percentage was given in the above figure. The overall combined result states that compensatory errors are seen less in children who have underwent for the early palatal surgery than in late palatal surgery. Finally the results shows that the children who are undergoing for Earlier palatal surgery I.e., before 2 years of age may tent to have less compensatory errors when comparing it with the children who have undergone for surgery after 2 years. The study states that earlier the surgery done, less compensatory errors and better results are seen. 


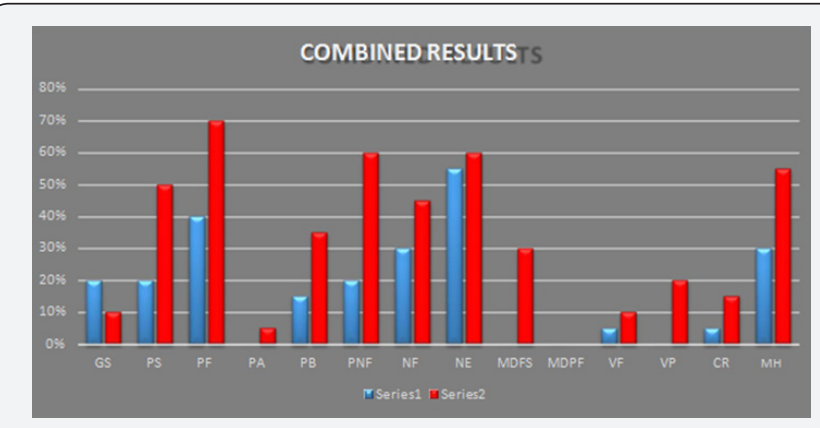

Figure 7: Represents the mean percentage of the occurrence of the compensatory errors in both the group children.

\section{Discussion}

The current study examined the effect of compensatory errors on the age of surgery in subjects with repaired cleft lip and palate, to determine there were any statistical differences across the errors in both groups. The present discussion addressed the effect of compensatory errors in relation to their age of surgery with the mean scores as a function of their place of articulation and manner of articulation in both groups between early and late palatal surgery in subjects with repaired cleft lip and palate. There have been very few studies in relation to the surgeries and compensatory errors which have been discussed in review. The present aim of the study is to see how impact the compensatory errors on the age of surgery. Here in this study they are divided into two groups to show the differentiation and relation between the Early and Late surgical group in order to check with their errors. In this study the each variable is separately analyzed and it is compared with in two groups to show the differentiation. Here, let us discuss the each variable with the both groups separately.

\section{Group-1 Early Palatal Surgery}

In this group there are 20 subjects with bilateral repaired cleft lip and palate. The controlling variables are controlled as much as possible. In this group all the subjects are underwent for the complete palatal surgery before 2 years with mean (1.87).

Glottal Stops (G.S): In this group the G.S is seen in 4 (100\%) children. Among them 3 children with Bilabial placement of /p/ voiceless sounds are replaced with the G.S and 1 child for alveolar /t/ voiceless sound is replaced with the G.S. Jonees; Chapman \& Hardin Jones [12] study also supports this result. In this it also shows that the children who are taking therapy from 1 year have less compensatory errors than who is taking from 2 years. Over all, the G.S are present with (20\%) in this group.

Pharyngeal Stop (P.S): In this group the P.S is seen in 4 children .In this all the children with velar placement of /k, g/ Voiced and voiceless sounds are replaced with the P.S. In this all this 4 children are attending for therapy from between 1-7 years. Overall, the P.S are present with (20\%) in this group.
Pharyngeal Fricatives (P.F): In this group the P.F is seen in 9 children. Among them 3 children with the alveolar placement of /s,z/ voiced and voiceless sounds and 4 children with oral affricates of post alveolar placement / ts, d $\mathrm{b} /$ voiced and voiceless sounds and 2 children with post alveolar placement of /ts, ds/ voiced and voiceless sounds are replaced with the P.F. Rullo, Maggio, Addabbo, Rullo, Festa, Perillo [20] Study also support this results. Overall, the P.F are present with (45\%) in this group.

Palatal Backing (P.B): In this group the P.B is seen in 3 children. Among them 1 child with alveolar placement of $/ t /$ voiceless sound and 2 children with retroflex placement of $/ \mathrm{d}_{\mathrm{o}} /$ voiced sounds are replacing as a P.B sound .In this children are attending therapy from 4-5 years. Overall, the P.B is present with $(15 \%)$ in this group.

Posterior Nasal Fricative (PNF):- In this group the PNF is seen in 4 children. Among them 3 children with oral affricates with post alvelor placement of $/ \mathrm{t} /$ voiceless sound and 1 child with alveolar placement of /s/ voiceless sound is replaced with the PNF. Kawano et al. 1985 study also support these results. These children are attending therapy from 3-9.4 years. Overall, the PNF is present with (20\%) in this group

Nasal Fricative (NF): In this group the NF is seen in 6 children. Among them 4 children with alveolar placement of /s/ voiceless sound is produced with the voiced alveolar nasal sound and 2 children with velar placement of $/ \mathrm{k} /$ voiceless sound is produced with the voiced alveolar nasal sound. These children are attending therapy from 1-10 years. Cohn and Mc Williams 1983 [15] study supports these results. Over all 30\% of NF are present in this group. Overall, the NF is present with (30\%) in this group.

Nasal Emissions (NE): In this group the NE is seen in 11 children .Among them 5 children has NE in Stops at Bilabial and alveolar placement, and 3 children has NE in Fricatives at labiodental and dental placements, and 3 children has NE in Affricates at post alveolar placements in both voiced and voiceless sounds. In this 2 children have VPI problem and 4 children have mildmod nasality. This people are attending therapy from 1-9.4 years. Rullo, Maggio, Addabbo, Rullo, Festa, Perillo [20] Study also support this results. Overall, the NE is present with (55\%) in this group.

Velar Fricative (VF): In this group the VF is seen in 1 $(100 \%)$ child. In this the child produces the sound at velar placement of $/ \mathrm{k} /$ voiceless sound at the same placement but it is substituted with the sibilant Fricative voiceless sound /s/ at alveolar placement. This child is attending therapy from 6 years. Overall, the VF is present with (5\%) in this group.

CLUSTER REDUCTION (CR): In this group the CR is seen in 1 child. In this the child produces the alveolar placement of / $\mathrm{t}$ voiceless sound in reduction of word. In this child is taking 
therapy from 8 years. Overall, the CR is present with (5\%) in this group.

Hypernasality: In this group 6 children are having mild hypernasality. In this 2 are with VPI problem and 4 children are diagnosed with mild-mod nasality. These children are attending therapy from 1-9.4 years. Overall, there are (30\%) of children with hypernasality in this group. The other compensatory errors like P.A, MDFS, MDPF, and VP were not present in this group.

\section{Group-2 Late Palatal Surgery}

In this group there are 20 subjects with bilateral repaired cleft lip and palate. The controlling variables are controlled as much as possible. In this group all the subjects are underwent for the complete palatal surgery After 2 years till 4 years (3.95\%) was considered.

Glottal Stops (G.S): In this group there are 2 children, both are having G.S, and both are using the velar placement of /g/ voiced sound as a G.S. Cohn and Mc Williams [22] and Trost [15] study also support this result. These children are attending therapy from 8 months -2 years. Over all $(10 \%)$ of children are having G.S in this group.

Pharyngeal Stop (P.S): In this group there are 9 children. Among them 3 children with velar placement of $/ \mathrm{k} /$ voiceless sound, and 1 child with velar placement of /g/ voiced sound, and 5 children with velar placement of both / $\mathrm{k}, \mathrm{g} /$ voiced and voiceless sounds are replaced with the P.S. In this the children are attending therapy from 2-9.5 years. Overall (50\%) of children are having P.S in this group.

Pharyngeal Fricative (P.F): In this group there are 14 children. Among them 5 children with alveolar placement of/s/ voiceless sound, and 6 children with post alveolar placement of $/ \int /$ voiceless sound, and 3 oral affricates of post alveolar placement $/ \mathrm{t}, \mathrm{d} / \mathrm{s}$ of both voiced and voiceless sounds are replaced with the P.F. Rullo, Maggio, Addabbo, Rullo, Festa Perillo [22] Study also support this results. In this the children are attending therapy from 6-11 years. Overall (70\%) of children are having P.F in this group.

Pharyngeal Affricates (P.A): In this group there is 1 child with P.A and this child with post alveolar placement of $/ \mathrm{t} /$ of voiceless sound is replaced with P.A. Rullo, Maggio, Addabbo, Rullo, Festa Perillo [22] \& Cohn and Mc Williams [15] study is supporting this result. In this the child is attending therapy from 7.5 years. Overall (5\%) of children are having P.A. in this group.

Palatal Backing (P.B): In this group there are 7 children with P.B. Among them 4 children with alveolar placement of /t, d/ of both voiced and voiceless sounds and 2 children with retroflex placement of / $t$ / of voiceless sounds, and 1 child with glide - palatal placement $/ \mathrm{j} /$ of voiceless sound is replaced with the P.B. In this the children are attending therapy from 2-9 years. Overall (35\%) of children are having P.B in this group.
Posterior Nasal Fricative (PNF): In this group there are 12 children with PNF. Among them 6 children with post alveolar placement of $/ \mathrm{J} /$ of voiceless sound, and 4 children with alveolar placement of /z/ voiced sound, and 2 children with alveolar placement /s/ of voiceless sound is replaced with the PNF. Kawano et al. [9] \& Chapman K L [14] studies also support these results. In this the children are attending for speech therapy from 2.5 -9.5 years. Overall (60\%) of children are having PNF in this group.

Nasal Fricatives (N.F): In this group there are 9 children with N.F. Among them 4 children with alveolar placement /s/ voiceless sound and glottal placement /h/ voiceless sound, and 3 children with velar placement $/ \mathrm{k}, \mathrm{g} /$ of both voiced and voiceless sounds and 2 children with fricative placement /s, z/ of both voiced and voiceless sounds are replaced with the NF. In this the children are attending speech therapy from 2-11 years. Cohn and Mc Williams 1983 study supports these results. Over all (45\%) of NF are present in this group.

Nasal Emissions (N.E): In this group there are 12 children with NE. Among them 5 children are having N.E in stops at alveolar and retroflex placements and 4 children are having N.E in Trill at alveolar placement/r/ of voiced sound and in fricatives at post alveolar placement $/ \mathrm{J} /$ of voiceless sound and 3 children are having N.E in affricates at post alveolar placement $/ \mathrm{t} /$ of voiceless sounds are replaced with the N.E. In this the children are attending to speech therapy from 8 months - 9.5 years. Rullo, Maggio, Addabbo, Rullo, Festa Perillo [22] study also support this results. Overall (60\%) of children are having N.E in this group.

Mid-Dorsum Fricative Stops (MDFS): In this group there are 6 children with MDFS in this group. Among them 3 children with post alveolar placement $/ \mathrm{J} /$ voiceless sounds and 2 children with fricatives at alveolar placement /s/ of voiceless sounds and 1 child with oral affricates at post alveolar placement $/ \mathrm{t} /$ of voiceless sounds are replace with the MDFS. In this children are attending speech therapy from 6-9 years. Morley 1970 \& Kawano et.al 1985 studies also support these results. Overall (30\%) of children are having MDFS in this group.

Velar Fricatives (V.F): In this group there are 2 children with V.F. In this both the children produces the velar sounds but substituted with fricatives at alveolar placement /s/ of voiceless sounds and post alveolar / $\mathrm{J} /$ of voiceless sounds and affricates at post alveolar / $\mathrm{g} /$ of voiceless sounds are replaced with the V.F. In this the children are attending speech therapy from 8months-2 years. Overall, (10\%) of children are having V.F in this group.

Velar Palatal (V.P): In this group there are 4 children with V.P. Among them 3 children with alveolar placement / $/$ / of voiceless sound, and 1 child with glide at palatal placement / $\mathrm{j} /$ of voiceless sounds are replaced with the V.P. In this the children are attending therapy from 4-9 years. Overall, (20\%) of children are having V.P in this group. 
Cluster Reduction (C.R): In this group there are 3 children with C.R. In this the child produces the alveolar placement of / $\mathrm{t} /$ voiceless sound in reduction of word. In this the children are attending therapy from 3.7- 10 years. Overall (15\%) of children are having C.R in this group.

Hypernasality: In this there are 11 children with hypernasality. Among which 4 children are complained of having VPI and other are diagnosed as mild - mod nasality. In this children are taking speech therapy from 8months -11 years. Overall (55\%) of children are having hypernasality in this group. Only the one MDPF Error was not present in these group children.

From GROUP-1 \& GROUP-2, the results states that the children who are receiving complete palatal surgery before 2 years are having less compensatory errors when comparing with the children who are receiving surgery after 2 years. The G.S are present in children in early surgery than in late surgery .It also states that the children who are receiving speech therapy at earlier stage are having less compensatory errors than who are taking it late.

In the present study they still compensating the errors may be because of many factors like dental occlusion, VPI, nasality due to which their speech is not audible with normal intelligibility, lack of stimulation at home, parental care, attending to therapy late, this are all may be the factors for which still they are compensating the errors. Thomas 2001 literature also support this study by stating that children who have undergone for palatal closure before 6months are less effected with their compensatory articulation errors when compaired with later 6 months. Therefore, the present study also states that the children are having less compensatory errors in children who are receiving complete palatal surgery before 2 years than later 2 years.

NOTE: Results states that compensatory errors are seen less in early palatal surgery (before $2 y$ ) children than in the children who went with late palatal surgery (after $2 y$ ).

\section{Conclusion}

The results of this study suggest a complex relationship between the compensatory errors and the age of complete palatal surgery. Although most of the children had surgery after the onset of the meaningful speech there was a considerable individual variation in children's overall articulation proficiency. The findings of compensatory articulation error test analysis of 40 children with repaired cleft lip and palate were considered with the two different surgical groups I.e., Early palatal surgery before $2 y r s$ and late palatal surgery after $2 y r s$ was discussed. It was found that there are less compensatory errors are present in children who received early palatal surgery before 2yrs than in the late surgery after 2 yrs .The characteristics of the each error were described. a. Implication of the present study: The study provides data on the compensatory errors in Telugu speaking children. The study provides data on the compensatory errors in bilateral repaired

\section{b. Cleft lip and palate}

i. The study provides the data on compensatory errors in children who have undergone for surgery early I.e. before $2 y$ and also who have undergone with late surgery i.e. after $2 \mathrm{y}$.

ii. The study is focused to emphasis the impact of surgery and compensatory errors.

\section{Clinical Implications}

i. Earlier the surgery done and no compensatory errors are present then the child should train with the normal developmental patterns.

ii. Earlier / later the surgery done and compensatory errors exits then the therapist should first remove the compensatory errors and then train with the normal patterns.

\section{Limitations}

i. No specific standard test material/word list is presented to assess the error types in children with cleft lip and palate.

ii. No objective test is used.

\section{Future Implication}

i. As there is no any standard test material specially for assessing compensatory errors next researcher can invent a standard word list specially for assessing compensatory errors.

ii. It can be done on large groups.

iii. Objective measurements can also be done.

iv. It can also check the children with unilateral cleft lip and palate.

v. It can also co-relate with their speech outcomes.

\section{References}

1. Jones CE, Chapman KL, Hardin-Jones MA (2003) Speech development of children with cleft palate before and after palatal surgery. Cleft Palate Craniofacial J 40(1): 19-31.

2. KL Chapman (2004) Is presurgery and early post-surgery performance related to speech and language outcomes at 3 years of age for children with cleft palate? Clin Linguist Phon 18(4-5): 235-257.

3. KL Chapman, MA Hardin (1992) Phonetic and phonological skills of two-year-olds with cleft palate. Cleft Palate Craniofac J 29(5): 435-443.

4. P Grunwell, J Russell (1988) Phonological development in children with cleft lip and palate. Clin Linguist Phon 2: 75- 95.

5. MM O'Gara, JA Longemann (1988) Phonetic analyses of the speech development of babies with cleft palate. Cleft Palate J 25(2): 122-134. 
6. VJ Russell, P Grunwell (1993) Speech development in children with cleft lip and palate, in: P. Grunwell (Ed.), Analysing Cleft Palate Speech, Whurr Publishing, London, UK, p. 19-47.

7. K Chapman, M Hardin-Jones, J Schulte, KA Halter (2001) Vocal development of 9-month-old babies with cleft palate. J Speech Lang Hear Res 44(6): 1268-1283.

8. DA Olson (1995) A descriptive study of the speech development of a group of infants with unoperated cleft palate, unpublished doctoral dissertation, North-western University, Evanston, IL, USA.

9. K Chapman (1991) Vocalizations of toddlers with cleft lip and palate. Cleft Palate Craniofacial J 28: 172-178.

10. Hardin-Jones MA, Chapman KL, Wright J, Halter KA, Schulte J, et al., (2002) The impact of early palatal obturation on consonant development in babies with unrepaired cleft palate. Cleft Palate Craniofacial J 39(2): 157-163.

11. MA Hardin-Jones, D Jones (2005) Speech production of pre-schoolers with cleft palate. Cleft Palate Craniofacial J 42(1): 7-13.

12. McWilliams B, Morris H, Shelton R (1990) Cleft Palate Speech. PA: Decker, Philidelphia, USA.

13. Albery L, Enderby P (1984) Intensive speech therapy for cleft palate children. Br J Disord Commun 19: 115-124.

14. Watson A, Sell D, Grunwell P (2001) Management of Cleft Lip and Palate. London: \& Whurr. Bender PL. Genetics of cleft lip and palate. Pediat Nurs 15: 242-249.

15. Jensen BL, Kreibord S, Dahl E, Fogh-Anderson P (1988) Cleft lip and palate in Denmark 1976-1981: epidemiology, variability and early somatic development. Cleft Palate J 25: 258-269.

16. Riski JE, DeLong E (1984) Articulation development in children with cleft lip/palate. Cleft Palate J 21: 57-64.

17. Haapanen ML (1994) Cleft type and speech proficiency. Folia Phoniatr Logop 46: 57-63.

18. Peterson-Falzone S, Hardin-Jones M, Karnell M, (eds). (2001) Cleft Palate Speech, (3 ${ }^{\text {rd }}$ edn). Mosby Elsevier, St. Louis, USA.

19. Chapman K, Hardin-Jones M, Halter KA (2003) Relationship between early speech and later speech and language performance for children with cleft lip and palate. Clin Linguist Phon 17(3): 173-197.
20. Kuehn D, Moller K (2000) The state of art: Speech and language issues in the cleft palate population. Cleft Palate-Craniofacial J 37(4):348-361.

21. Wu J, Chen YR, Noordhoff MS (1988) Articulation proficiency and error patterns of cleft palate children with delayed hard palate closure. Ann Acad Med Singapore 17: 384-387.

22. Weatherley-White RC, Eiserman W, Beddoe M, Vanderberg R (2005) Perceptions, expectations, and reactions to cleft lip and palate surgery in native populations: A pilot study in rural India. The Cleft PalateCraniofacial Journal 42(5): 560-564.

23. Starr CD, Moller KT, Dawson W, Graham J, Skaar S (1984) Speech ratings by speech clinicians, parents, and children. Cleft Palate J 21: 286-292.

24. Solé MJ (1992) Phonetic and phonological processes: The case of nasalization. Language and Speech 35(1-2): 29-43.

25. Sell D, Harding A, Grunwell P (1999) Revised GOS.SP.ASS '98: an assessment for speech in children with cleft palate and/or velopharyngeal dysfunction. Int J Lang Commun Disord 34: 17-33.

26. Sell D, Grunwell P (1993) Speech in subjects with late operated cleft palate. In P. Grunwell (Ed.), Analysing Cleft Palate Speech. Whurr, London, UK, pp. 112-141.

27. Sell D, Grunwell P (1990) Speech results following late palatal surgery in previously unoperated Sri Lankan adolescents with cleft palate. Cleft Palate J 27(2): 162-168.

28. Peterson-Falzone S, Hardin-Jones M, Karnell M (2000) Cleft Palate Speech. Mosby, Philadelphia, USA.

29. Morris HL (1978) The Bratislava Project: Some results of cleft palate surgery. University of Iowa Press, Iowa City, USA.

30. Babu RM, Rathna N, Bettagiri R (1972) Test of articulation in Kannada Journal of AIISH 3: 64-79.

31. Bzoch KR (1965) Articulation proficiency and error patterns of preschool cleft palate and normal children. Cleft Palate J 2(4): 340-349.

32. Bzoch KR (1979) Communicative Disorders Related to Cleft Lip and Palate, $\left(2^{\text {nd }}\right.$ edn). Little Brown, Boston, MA, USA.

33. Counihan DT (1960) Articulation skills of adolescents and adults with cleft palate. Cleft Palate J 25: 181-187

\section{Your next submission with Juniper Publishers will reach you the below assets}

- Quality Editorial service

- Swift Peer Review

- Reprints availability

- E-prints Service

- Manuscript Podcast for convenient understanding

- Global attainment for your research

- Manuscript accessibility in different formats

( Pdf, E-pub, Full Text, Audio)

- Unceasing customer service

Track the below URL for one-step submission

https://juniperpublishers.com/online-submission.php 